\title{
Evaluation of behavioral changes induced by a first step of domestication or selection for growth in the European sea bass (Dicentrarchus labrax): A self-feeding approach under repeated acute stress
}

\author{
S. Millot ${ }^{a,}{ }^{*}$, S. Péan ${ }^{a}$, D. Leguay ${ }^{a}$, A. Vergnet ${ }^{b}$, B. Chatain ${ }^{b}$ and M.-L. Bégout ${ }^{a}$ \\ a Ifremer, Place Gaby Coll, BP 5, 17137 L'Houmeau, France \\ b Station expérimentale d'aquaculture, Ifremer, chemin de Maguelone, 34250 Palavas-les-Flots, France \\ *: Corresponding author : S. Millot, Tel.: +33 546509 440; fax: +33 546500 600, email address : \\ sandiemillot@yahoo.fr
}

\begin{abstract}
:
Among other strategies to improve fish welfare in rearing environment, domestication and/or selective breeding was proposed to minimize fish responsiveness to husbandry practices. To verify this hypothesis on a recently domesticated specie, the sea bass, Dicentrarchus labrax, L., an experiment was realized, using four populations differing according to their level of domestication or selection: one population produced from wild parents (Wild), one population produced from parents domesticated for one generation (Domesticated) and two produced from parents selected for growth for one generation (Selected $A$ and Selected $B$ ). The experiment was carried out over 91 days with 600 fish (50 fish per tank, 150 fish per population). After a control period, the fish were submitted from day 35 and during 56 days to a stress treatment including frequent and random application of 4 acute stressors (pursuing fish with a net during $1 \mathrm{~min}$, switching off the light for $2 \mathrm{~s}$ during the day or, conversely, switching on the light for $2 \mathrm{~s}$ during the night, and overflying a bird predator silhouette above the tank during $30 \mathrm{~s}$ ). The two variables that were measured, i.e.: fish self-feeding behavior and growth performance [at days (D) $14,35,63$, and 91] were both altered, albeit differentially according to populations, by the stress treatment. During the first stress period (from D35 to D63), all groups modified their feeding rhythm and highly increased their feed intake while their growth rate decreased (Domesticated and both Selected fish groups) or remained stable (Wild). During the second stress period (from D64 to D91) fish continued to modify their feeding rhythm (being more and more diurnal) and increased again their feed intake; conversely to what happened during the first stress period, here, these modifications were associated with an improvement of the growth rate of all populations. During the whole experiment, both Selected groups and Domesticated fish were always characterized by a higher body mass, specific growth rate and body condition factor than Wild fish. In conclusion, and according to the results of this study, a first generation of domestication or selection improved fish growth performance but, at this early stage do not modify behavioral responses to repeated acute stress exposure.
\end{abstract}

Keywords: Feed intake; Feeding rhythm; Specific growth rate; Adaptation capacities; Welfare 


\section{Introduction}

Fish domestication can be defined as "the process by which a population of animals becomes adapted to humans and to the captive environment by some combination of genetic changes occurring over generations and environmentally induced developmental events reoccurring during each generation" (Price, 1984). Selection is usually used to improve traits strongly associated to production cost (e.g. growth rate, disease resistance, age at maturity, flesh quality), but very little is known on selected fish capacities to tolerate stress per se. It was nevertheless shown that fish responsiveness to stress has a genetic component that could be, therefore, modified by selective breeding (Pottinger and Pickering, 1997). Indeed, (Pottinger and Pickering, 1997) and (Pottinger and Carrick, 1999) have shown that it was possible to select rainbow trout (Oncoryhnchus mykiss, Walbaum) strains presenting a high or low cortisol response to confinement stress. These strains have also shown other clear behavioral and physiological differences such as a quicker resumption of feeding, when placed in a novel environment, for the low cortisol responding strain ([Overli et al., 2004] and [Overli et al., 2002]), and a lower brain serotonin concentration (Overli et al., 2005). According to these results, it seems feasible to generate strains displaying a high stress tolerance, and thus, improved performances in aquaculture, 
across a number of traits (e.g. improvement of feed conversion efficiency, growth, fecundity, egg quality, post-slaughter flesh quality and also reduction in the incidence of disease), and in addition an improvement of their welfare (Pottinger \& Pickering, 1997).

The sea bass (Dicentrarchus labrax, L.) is an important species in Mediterranean and Atlantic aquaculture that was recently domesticated. Therefore, very little is known on effects of the very early step of domestication or selection for growth apart from classical traits of commercial interest (Dupont-Nivet et al, 2008; Vandeputte et al., 2009) and specially nothing is know, on behavioral responses to stress exposure and welfare potential. Though, stress is an unavoidable component of finfish aquaculture environment (Pottinger \& Pickering 1997), and is also largely associated to fish welfare, which is an important issue for the industry, not just for public perception, marketing and production acceptance, but also often in terms of production efficiency, quality and quantity (Broom, 1998; Southgate \& Wall, 2001; Huntingford et al., 2006). Therefore, even if stress responses do not highlight all welfare disturbances, it is generally admitted that they strongly indicate a poor welfare (Broom, 1988; Huntingford et al., 2006). Such evidences led to an active research on potential methods to reduce stress responses in aquaculture species (Ashley, 2007). Among them, domestication and selective breeding to minimize fish responsiveness to stressors, was a major axis of research of the last few years (Pottinger, 2003).

The present study thus proposes to evaluate the early effect (one generation) of fish domestication and selection for growth on behavior changes. The chosen approach was an evaluation of the modifications induced in self-feeding (feed demand rhythm, quantities of food intake and wasted) by repeated acute stress exposure (stress tolerance used as a 
screening procedure). Growth performance (body mass, body condition factor, specific

101 growth rate) was recorded as complementary traits.

\section{Material and methods}

\subsection{Experimental set up}

The four populations from where the fish tested in this experiment were sampled, were

108 produce to evaluate the response to selection for growth in the frame of a genetic EU project 109 (Competus COOP-CT-2005-017633) and the details of rearing conditions and sizes of these 110 populations can be found in Vandeputte et al., 2009. In summary, the four tested populations

111 have been hatched and reared at the experimental research station of Ifremer in Palavas-les-

112 Flots (France). Until the start of the experiment, fish were reared according to sea bass rearing 113 standards (Chatain, 1994). They were produced from a full factorial crossing (each female 114 was crossed with each male) of 13 wild Mediterranean females with (i) 20 Atlantic wild 115 males (Wild group; which will represent here the "control" strain of the experimental design) 116 (ii) 20 Atlantic domesticated males (Domesticated group), (iii) 19 and (iv) 17 Atlantic males 117 selected for growth according to different procedures (Selected $A$ and $B$ groups). The Wild 118 parental males were chosen among an Atlantic wild population kept in captivity for one to

119 three years. The domesticated and the Selected A males have been obtained by choosing fish 120 in a population reared for two years (one generation) according to sea bass rearing standards 121 (Chatain, 1994): the domesticated ones were chosen at random while the selected ones were 122 the $5 \%$ longest fish at the same age (20 months, $400 \mathrm{~g})$. The Selected $B$ males were also the $1235 \%$ longest fish of this population but in a group that had undergone the PROSPER selective 124 procedure (Chevassus et al., 2004): fish graded at the age of 200, 444 and 685 days to be 
125 reared in homogeneous body mass class. Thus, all fish tested in this experiment never

126 experienced the natural environment, had the same life history, and only differed by their

127 male parent presenting different levels of domestication or selection:

$128 \quad$ - wild sires captive for at least one year (Wild group)

129 - sires, descendant of the previous wild parents that has completed an entire cycle of rearing

130 (i.e. first generation of domestication), and were chosen at random (Domesticated group)

131 or among the 5\% longest (i.e. first generation of domestication and selection; Selected A

132 and $B$ groups).

134 The present experiment was carried out with a triplicate per strain from 14/03/07 to 12/06/07.

135 The 12 tanks $\left(1 \mathrm{~m}^{3}\right.$ each) were supplied with semi-recirculated seawater; all tanks were in the

136 same room. For each tank, the flow rate was $4 \mathrm{~m}^{3} \mathrm{~h}^{-1}$ and the water renewal $30 \%$ per day.

137 Water temperature was maintained at $20.3 \pm 1.1^{\circ} \mathrm{C}$, oxygenation above $90 \%$ of saturation in

138 the water-outlet, and salinity was $36.3 \pm 1.5$. Water ammonia and nitrite compounds were

139 measured every day and were never above recommended levels for sea bass. Tanks were lit

140 by a neon lamps hanged $1.5 \mathrm{~m}$ above the water surface. Light regime was 16:8 LD (light

141 onset at 06:00) with twilight transition periods of $30 \mathrm{~min}$. Fish were fed a commercial diet for

142 sea bass (Neo Grower Extra Marin 5.0, France) containing $45 \%$ of crude protein and $20 \%$ of

143 lipid according to the manufacturer. The experiment was realized over 91 days with 600 fish

144 (50 fish per tank, 150 fish per strain). One tank of Selected $B$ fish has never learned to use the

145 self-feeder and was therefore removed from our analysis.

147 At the beginning of the study, fish were 24 months-old and four groups were randomly

148 sampled from the larger populations. Wild group weighted an average of $468 \pm 7 \mathrm{~g}$

149 (coefficient of variation $(\mathrm{CV})=17 \%, \mathrm{n}=150$ fish), Domesticated group an average of 
$443 \pm 6 \mathrm{~g}(\mathrm{CV}=18 \%, \mathrm{n}=150 \mathrm{fish})$, Selected $A$ group an average of $530 \pm 8 \mathrm{~g}(\mathrm{CV}=19 \%$,

$151 \mathrm{n}=150 \mathrm{fish})$ and Selected $B$ one an average of $523 \pm 10 \mathrm{~g}(\mathrm{CV}=20 \%, \mathrm{n}=100 \mathrm{fish})$. Fish

152 were again weighted (to the nearest $\mathrm{mg}$ and measured for length to the nearest $\mathrm{mm}$ ) 14 (D14),

15335 (D35), 63 (D63) and 91 (D91) days after the beginning of the experiment. Experimental

154 periods were defined as the period between two measuring day: P1 from D1 to D14; P2 from

155 D15 to D35; P3 from D36 to D63 and P4 from D64 to D91. All measuring days were done

156 under anesthesia using clove oil (0.08\%).

157 The feeder device comprised a screened type sensor (a metal rod protected by a PVC cylinder;

158 Covès et al., 2006; Millot et al., 2008) and a control box. After each actuation, fish were 159 rewarded with 25 pellets, feed dispensers thus achieving a mean distribution of 0.1 to

$160 \quad 0.08 \mathrm{~g} \mathrm{~kg}^{-1}$ fish at the beginning and at the end of the experiment respectively. Such a set up

161 allowed monitoring the number, the date and the hour of feed demand in each tank.

162 Each fish was implanted with a PIT-tag to follow individual body mass and length over time.

163 Fish were placed under self-feeding conditions at D1 and food access was possible during the

164 whole day along $(24 \mathrm{~h})$ even during waste counts from 10:00 to 11:00. Apparent feed 165 consumption within each tank (feed amount dispensed minus wasted pellets collected in the 166 sediment trap) was monitored daily. Triggering activity recordings were done continuously 167 for 77 days except $24 \mathrm{hrs}$ before and during fish handling (8 days off in total).

\subsection{Stress treatment}

After a first phase of rearing $(\mathrm{P} 1+\mathrm{P} 2)$, which represented the control phase of the experiment, stress events screening procedures were applied; P3 + P4 therefore represented

173 the phase of stress treatment. P1 + P2 was used to compare before versus after stress 174 treatment for all strains. Such an experimental design was chosen because all tanks were in 
175 the same room and same water circuit, and disturbances to one tank were unavoidably

176 transmitted to adjacent tanks. The stress treatment screening consisted in: pursuing fish with a

177 net during $1 \mathrm{~min}$, switching off the light for 2 s during the day or, in contrary, switching on the

178 light for $2 \mathrm{~s}$ during the night, and overflying a bird predator silhouette above the tank during

17930 s. To prevent any fish habituation, each stressor was applied randomly over time, fish

180 being not disturbed at all during some days, or, on the contrary, submitted to one, two or three

181 stress per day (with the same or with different stressors; Table 1).

182

\subsection{Statistics}

184

To account for fish growth in between periods, all feeding related variable were relative to

186 fish biomass.

187 The variables chosen to measure the different performances were the following:

188 - The amounts and the coefficient of variation of feed demanded (FD), intaken (FI) and

189 wasted (FW) (g per kg of biomass present in the tank and per day). These variables were

190 used to evaluate feeding behavior changes.

191 - The evolution over time of fish body mass $(\mathrm{g})$, body condition factor $\left(\mathrm{K} \mathrm{in} \mathrm{g} \mathrm{cm}^{-3}\right)$,

192 Specific Growth Rate (SGR in $\%$ day $^{-1}$ ), and Feed Efficiency (FE) allowed to appreciate

193 growth pattern modifications and to hypothesize changes in fish metabolic rate using feed

$194 \quad$ intake as a proxy.

195 - The amounts of feed demands per hour ( $\mathrm{g}$ per $\mathrm{kg}$ of fish biomass) was chosen to follow

196 the group feed demand rhythm and changes over time.

197

198

199 
- The specific growth rate was calculated as: SGR (\% body mass per day) $=100\left(\mathrm{Ln} \mathrm{M}_{\mathrm{f}}-\right.$

$\left.201 \quad \operatorname{Ln} M_{i}\right) \times t^{-1}$, where $M_{f}$ and $M_{i}$ are the final and the initial body mass $(g)$ respectively, and $t$

202 the total number of days.

203 - The body condition factor was calculated as: $\mathrm{K}\left(\mathrm{g} \mathrm{cm}^{-3}\right)=100 \times \mathrm{M} \mathrm{x} \mathrm{L}^{-3}$ where $\mathrm{M}$ is mass

204 (g) and L the standard body length (cm).

$205-$ The coefficient of variation was calculated as: CV $(\%)=100 \times \mathrm{SD}^{-1}$ where $\mathrm{SD}$ is 206 standard deviation and $\mathrm{X}$ is average.

207 - The feed efficiency (FE) was calculated from biomass and feed consumption: FE $=($ final 208 biomass $(\mathrm{kg})$-initial biomass $(\mathrm{kg})) \times(\text { feed intake }(\mathrm{kg}))^{-1}$.

209 All mean values were expressed with the standard error $( \pm \mathrm{SE})$.

211 Data were checked for normality with Shapiro-Wilk test and for homogeneity of variances 212 with the Bartlett's test; they all complied for parametric tests to be used. For fish body mass, 213 body condition factor and specific growth rate variables, a repeated ANOVA was used to 214 analyze the average differences between populations (fixed factor), periods (fixed factor), and 215 tanks (random factor nested to population). The different periods considered here were: 216 during the control phases; P1 and P2, and during the stress phases; P3 and P4. For the 217 variables related to feeding behavior, P1 was not included on the statistical analysis because 218 for each population, feed demand activity only began 14 days after the study started. 219 Therefore, for the amount of feed demanded, wasted or intaken, the same type of ANOVA 220 described above, was used but the periods considered here were only P2, P3 and P4. For the 221 feed demand rhythm, a repeated ANOVA was used to compare the differences between 222 populations (fixed factor), periods (fixed factor), hour (fixed factor) and tanks (random factor 223 nested to population). The number of data for this variable corresponded to the number of 224 recorded feeding day (68) x 24 hours x number of tank (11). Homogeneous groups were 
225 determined with a posteriori Newman and Keuls test (Dagnélie, 1975). For all tests, 226 significant threshold was $\mathrm{p}<0.05$, and analyses were performed using the Statistica software 227 (Statsoft, USA).

\section{Results}

During the experiment, some fish died for different reasons i.e. some jumped out of the tank or for unidentified causes, however, no mortality could be allocated to stress or anesthesia: it concerned 1 Wild fish during P1, 1 Wild and 1 Domesticated fish during P3; 2 Domesticated and 2 Selected $A$ fish during P4. These changes in the number of individuals were taken into account in all measured variables.

\subsection{Amount of feed demanded, intaken and wasted over time}

Wild fish systematically demanded $\left(\mathrm{F}_{3,703}=9.9, \mathrm{p}<0.001\right)$ and ate $\left(\mathrm{F}_{3,703}=9.7\right.$, $240 \mathrm{p}<0.001$ ) less than Selected $A$ and $B$ or Domesticated ones (Fig.1). During P2, Wild 241 demanded, and entirely ate, an average of $2.66 \pm 0.39 \mathrm{~g} \mathrm{~kg}^{-1}$ day $^{-1}$ while the three other groups 242 demanded in average $4.17 \pm 0.24 \mathrm{~g} \mathrm{~kg}^{-1}$ day $^{-1}$, ate $4.15 \pm 0.24 \mathrm{~g} \mathrm{~kg}^{-1}$ day $^{-1}$ and wasted $0.02 \pm$ $0.01 \mathrm{~g} \mathrm{~kg}^{-1}$ day $^{-1}$. During P3, demanded $\left(\mathrm{F}_{3,703}=27.8, \mathrm{p}<0.001\right)$ and intaken $\left(\mathrm{F}_{3,703}=28.1\right.$, $244 \mathrm{p}<0.001)$ food increased significantly for all groups. FD and FI being $3.97 \pm 0.41 \mathrm{~g} \mathrm{~kg}^{-1} \mathrm{day}^{-1}$ (no waste) for Wild and FD $=5.30 \pm 0.24 \mathrm{~g} \mathrm{~kg}^{-1}$ day $^{-1}$ and $\mathrm{FI}=5.25 \pm 0.24 \mathrm{~g} \mathrm{~kg}^{-1}$ day $^{-1}$ for the other groups. During P3, FW did not change for Selected B and Domesticated groups (0.02 \pm $0.01 \mathrm{~g} \mathrm{~kg}^{-1}$ day $\left.^{-1}\right)$ while it increased by 3 fold for Selected $A\left(0.09 \pm 0.04 \mathrm{~g} \mathrm{~kg}^{-1}\right.$ day $^{-1}$, which represented about $2 \%$ of the demanded amount; $\left.\mathrm{F}_{3,703}=2.2, \mathrm{p}<0.05\right)$. During $\mathrm{P} 4$, these 
group, and FD $=5.97 \pm 0.14 \mathrm{~g} \mathrm{~kg}^{-1} \mathrm{day}^{-1}$ and $\mathrm{FI}=5.95 \pm 0.14 \mathrm{~g} \mathrm{~kg}^{-1} \mathrm{day}^{-1}$ for the others; 251 their FW being $0.01 \pm 0.01 \mathrm{~g} \mathrm{~kg}^{-1} \mathrm{day}^{-1}$.

252 Observing the immediate day-to-day stressor effect on feeding behavior was difficult but the $253 \mathrm{CV}$ of feed intake $\left(\mathrm{CV}_{\mathrm{FI}}\right)$ highlighted fish appetite variation over each experimental period. 254 Thus, during P2, $\mathrm{CV}_{\mathrm{FI}}$ were equal to $89 \%, 33 \%, 55 \%$ and $53 \%$ for Wild, Domesticated, 255 Selected $A$ and $B$ respectively. During P3, Domesticated fish showed a slight $\mathrm{CV}_{\mathrm{FI}}$ increase $256(\mathrm{CV}=39 \%)$ while the three other populations showed a $\mathrm{CV}_{\mathrm{FI}}$ decrease $(\mathrm{CV}=45 \%, 35 \%, 47 \%$ for Wild, Selected $A$ and $B$ respectively). During P4, a high $\mathrm{CV}_{\mathrm{FI}}$ decrease was observed for all fish strains: $26 \%$ for Wild, $19 \%$ for Domesticated and $23 \%$ for Selected $A$ and $B$.

\subsection{Variations over time of fish growth and feed efficiency}

At the beginning of the study, selected $(A$ and $B)$ and non selected (Domesticated and Wild) fish presented a difference of $14 \%$ in body mass. Selected fish, nevertheless issued from a single generation of selection for growth were characterized by a growth improvement of $20 \%$, which is generally obtained in two generations of selection in most breeding programs dealing with fish (Vandeputte et al., 2009). This difference between selected and non selected fish was maintained more or less during the whole experiment; except at D91 where the difference of body mass was $13 \%$ with Domesticated and $19 \%$ with Wild $\left(\mathrm{F}_{12,2718}=3.3\right.$, $\mathrm{p}<$ 0.001; Fig.2 A). In general, fish lost body mass during P1 (-3\% for Domesticated and -7\% for 270 the other groups). Then, during P2 and P3 fish body mass slightly increased (around $+3 \%$ for 271 Wild strain and $+6 \%$ for the other strains). During P4, fish body mass increased rapidly 272 reaching a rate of $+9 \%$ for Wild group and $+12 \%$ for the others.

273 Whatever fish strain, gonads weighted an average of $0.23 \pm 0.02 \mathrm{~g}$ for males $(0.04 \% \mathrm{of} \mathrm{BW})$ and 3.56 $274 \pm 0.17 \mathrm{~g}$ for females $(0.59 \%$ of BW). These results highlighted that tested fish were not sexually 275 mature. 
276 Fish specific growth rate during P1 was negative for all groups, Selected $(A$ and $B)$ and Wild 277 populations being more affected than the Domesticated population $(-0.19 \pm 0.01$ and $278-0.08 \pm 0.01 \%$ day $^{-1}$ respectively; $F_{9,2172}=11.9, \mathrm{p}<0.001 ;$ Fig.2 B). During P2, all 279 populations showed a high SGR increase, the Wild group being the less performing. This 280 difference was maintained more or less during the whole experiment. During P3 the SGR of 281 Selected and Domesticated groups decreased significantly (around -25\%) while Wild SGR did 282 not really change (-5\%). Finally, during P4, the SGR of all strains highly increased, especially 283 in the Wild group (3 fold higher than during P3).

284 At D1, the body condition factor (K) of Selected A group was higher than in other populations $285\left(\mathrm{~F}_{12,2718}=4.9, \mathrm{p}<0.001\right.$; Fig.2 C). During P1, the K factor highly decreased in all populations 286 and at D14 Domesticated and Selected A were characterized by a higher body condition factor 287 than those of Selected B. During P2, only the Selected B group showed a significant body 288 condition factor increase (+3\%). During P3, the K factor was stable in all populations. Finally, 289 during P4, the $\mathrm{K}$ factor increased significantly for all groups except for Wild fish.

290 All populations had similar feed efficiency $(\mathrm{FE})$ during the whole experiment $\left(\mathrm{F}_{6,21}=0.5\right.$, $291 \mathrm{p}>0.05)$. However, even if the FE changes over time were not significant, the values varied 292 from $0.63 \pm 0.11$ during $\mathrm{P} 2$ to $0.35 \pm 0.14$ during P3 and returned to $0.60 \pm 0.05$ during P4.

\subsection{The daily rhythm of feeding activity}

As a general feature, all groups realized more feed demands during the night than 297 during the day period (Fig.3). However, some differences appeared between groups over time $298\left(\mathrm{~F}_{138,17664}=3.5, \mathrm{p}<0.001\right)$. According to the stress treatment timetable (Table 1$)$, the fish 299 feeding rhythm change did not correspond to the time where stressors were performed. 300 Indeed, no real difference appeared at 01:00, 04:00, 10:00 and 14:00. The changes seemed 
more correlated to dawn (06:00) and dusk (22:00) and more visible when the data were analyzed by period. Thus, during P2, fish realized 53\% (Wild), 56\% (Selected B), 77\% (Selected A) to $94 \%$ (Domesticated) of their feed demands during the night period with a peak at 22:00. During P3, the percentage of feed demands during the night period decreased but the majority was still nocturnal for all groups (51\% for Wild, 54\% for Selected B, 69\% for

306 Selected $A$ to $79 \%$ for Domesticated) with again a peak at 22:00. However, all populations 307 increased their feed demands activity at 06:00 (3 fold more for Selected B and Wild; 4 fold more for Selected and 20 fold more for Domesticated). During P4, the feed demands during the night period decreased again and especially for Selected fish which were characterized at this moment by a diurnal feeding (69\% for Selected B and 59\% for Selected A). Domesticated

311 fish increased also their diurnal feed demands ( $+46 \%$ at $06: 00)$ but continued to realize $75 \%$

312 of their feed demands during the night period. Wild fish, on the contrary, showed an increase 313 of their nocturnal feed demands $(+17 \%)$ and a decrease of their feed demands at 06:00 $314(-11 \%)$

\section{Discussion}

318 At the beginning of the experiment fish were naive facing the self-feeder and whatever the 319 group they really began to correctly activate it after 14 days. This period was thus synonym of 320 food deprivation and as a consequence, characterized by a loss of fish body mass, a negative 321 growth rate and a decrease of $\mathrm{K}$ factor for all populations. The loss of body mass during this 322 period was comparable between Selected A, B and Wild groups indicating an analogous 323 metabolic utilization that was higher than that of the Domestic group. During the second part 324 of the control period, all groups showed an increase of their growth performance especially noticeable in Selected and Domesticated fish. As for brown trout (Salmo trutta, L.; Mambrini 
et al., 2004), sea bass were able to display compensatory growth after a long period of food

327 deprivation. In the different salmonid species studied so far, this growth compensation is realized by an increase of feed intake (Bull and Metcalfe, 1997; Bull et al., 1996; Metcalfe and Thorpe, 1992), feed efficiency (Boujard et al., 2000; Dobson and Holmes, 1984; Kindschi, 1988; Quinton and Blake, 1990) or both (Miglavs and Jobling, 1989). In our study,

331 the growth increase was mainly attributable to an increase in feed intake (during this period,

332 Selected and Domesticated fish ate 57\% more food than Wild fish), with no effect on feed 333 efficiency. It can therefore be put forward that, as observed by Mambrini et al. (2004) on

334 brown trout, feed efficiency in sea bass is not affected by a first generation of domestication 335 or selection for growth processes.

337 The rhythm of feeding activity confirms that sea bass do not feed continuously during the day 338 (Sánchez-Vázquez et al., 1995). They displayed a nocturnal feeding behavior with an 339 important peak of feed demands at dusk (22:00) especially for Selected and Domesticated 340 fish. This result was in accordance with the observation of Mambrini et al. (2004) on brown 341 trout, showing that feeding rhythm was affected significantly by the line, the peak of feeding 342 being more pronounced for Selected fish than for control ones. Repeated intermittent acute 343 stressors are generally admitted to alter behavior (Pickering \& Pottinger, 1989; Pankhurst \& 344 Van der Kraak, 1997), the most common change in fish being a reduction of the feeding 345 activity during the stress period (Pickering et al., 1991; Farbridge \& Leatherland, 1992, 346 Pankhurst \& Van der Kraak, 1997) associated with a growth rate reduction (Pickering \& 347 Stewart, 1984; McCormick et al., 1998; Liebert \& Schreck, 2006). However, in our study, 348 none of the sea bass groups exposed to a repeated stress treatment screening presented a 349 reduction in feeding activity but, on the contrary, a significant increase of feed demand and 350 intake during the first stress treatment period $(+49 \%$ for Wild and $+30 \%$ for Selected and 
Domesticated) leading for Selected $A$ fish to a wastage that was already suggested as an

352 indicator of stress level by Millot et al. (2008). This period was also characterized by a high

353 feed intake CV, which seemed to indicate an important perturbation of fish feeding behavior.

355 During the second period of stress, all fish groups showed again an increased of feed intake $356(+28 \%$ for Wild and $+12 \%$ for Selected $A$ and $B$ or Domesticated $)$, of SGR, of body mass and 357 of body condition factor (except for Wild fish) and a high decrease of feed intake CV. During 358 this period, food wastage for the Selected $A$ fish returned to the level observed before any 359 stressor application. Moreover, at the same time, the feed efficiency of all populations reached 360 again the level observed before the stress period (0.60). All these observations could be 361 explained by fish adaptation to stress treatment challenge according to two processes: 1) 362 habituation, which is characterized by a progressive decrease of the animal response to an 363 unreinforced stimulus (stressor) presented repeatedly or continuously (Humphrey, 1933; 364 Thorpe, 1963; Hinde, 1970; Peeke \& Petrinovich, 1984), and/or 2) a compensation for a 365 higher metabolic rate caused by stress through an increase of feed intake. This adaptation was 366 also accompanied by a feeding rhythm change, where fish presented a more and more diurnal 367 pattern. This observation was particularly true for Selected and Domesticated fish which were 368 also characterized by a higher body mass, SGR and K factor than Wild fish at the end of the 369 experiment. These results, thereby plead in favor of a modification of the feeding rhythm to 370 adjust meal timing to the metabolic rate variations imposed by stressors in order to improve 371 food utilization and assimilation, as previously showed by Spieler (1977) and Parker (1984) 372 on mammals.

\section{5. Conclusion}


376 The results of this study, pointed out that the improvement of growth performance induced by

377 a first generation of domestication or selection for growth in sea bass was mainly due to a

378 higher appetite rather than a better feed efficiency but that, at this early stage, behavioral

379 responses to repeated acute stress were not modified. Finally, to better evaluate the effects of

380 domestication or selection processes, it will be useful to investigate, in future experiments, the

381 effect of additional generations for which the rearing condition pressure would be enhanced.

382 Furthermore, if one goal in the future is to select fish for stress tolerance, it will be necessary

383 to develop dedicated indicators (traits) on which selection pressure could be made.

385 Acknowledgements

386 This work was performed within the Integrated Research Project SEAFOODplus, contract no.

387 FOOD-CT-2004-506359 and the STREP Project FASTFISH, contract no. 022720. It is part of 388 the program of the GDR Ag $\pi$, INRA-Ifremer research group for sustainable fish breeding.

389 The financing of this work by the European Union and by the county council of Charente 390 Maritime is gratefully acknowledged. This study was conducted under the approval of the 391 Animal Care Committee of France under the official licence of M.L. Bégout (17-010).

392 The fish that were tested here were issued from the COMPETUS project, funded by Ardag 393 Red Sea Mariculture (Eilat, Israel), Ecloserie Marine de Gravelines (Gravelines, France), Les 394 Poissons du Soleil (Balaruc, France), Tinamenor SA (Pesues, Cantabria, Spain), Viveiro 395 Vilanova (Vila Nova de Milfontes, Portugal) and the European Union (project COOP-CT396 2005-017633).

\section{References}

399 Ashley, P.L., 2007. Fish welfare: current issues in aquaculture. Appl. Anim. Behav. Sci. 104, 400 199-235. 
Boujard, T., Burel, C., Médale, F., Haylor, G., Moisan, A., 2000. Effect of past nutritional history and fasting on feed intake and growth in rainbow trout Oncorhynchus mykiss. Aquat. Living Resour. 13, 129-137.

Bull, C.D., Metcalfe, N.B., 1997. Regulation of hyperphagia in response to varying energy deficits in overwintering juvenile Atlantic salmon. J. Fish Biol. 50, 498- 510.

Bull, C.D., Metcalfe, N.B., Mangel, M., 1996. Seasonal matching of foraging effort to anticipated energy requirements in anorexic juvenile salmon. Proc. R. Soc. London B 263, $13-18$

Broom, D.M., 1988. The concept of stress and welfare. Recueil De Médecine Vétérinaire 164, 715-721.

Chatain, B., 1994. Estimation et amélioration des performances zootechniques de l'élevage larvaire de Dicentrarchus labrax et de Sparus auratus. Thèse de Doctorat d'Etat, Univ. d'Aix-Marseille II 199 pp.

Chevassus, B., Quillet, E., Krieg, F., Hollebecq, M.-G., Mambrini, M., Fauré, A., Labbé, L., Hiseux, J.P., Vandeputte, M., 2004. Enhanced individual selection for selecting fast growing fish : the «PROSPER » method, with application on brown trout (Salmo trutta fario). Genet. Selec. Evol. 36, 643-661.

Covès, D., Beauchaud, M., Attia, J., Dutto, G., Bouchut, C., Bégout Anras, M.-L., 2006. Long-term monitoring of individual fish triggering activity on a self-feeding system: An example using European sea bass (Dicentrarchus labrax). Aquaculture 253, 385-392.

Dagnélie, P., 1975. Théorie et méthodes statistiques. In : Applications agronomiques vol. 2, 463 pp. Presses Agronomiques de Gembloux, Gembloux.

Dobson, S.H., Holmes, R.M., 1984. Compensatory growth in rainbow trout, Salmo gairdneri Richardson. J. Fish Biol. 25, 649-656. 
Dupont-Nivet M., Vandeputte M., Vergnet A., Merdy O., Haffray P., Chavanne H., Chatain B., 2008. Heritabilities and GxE interactions for growth in the European sea bass (Dicentrarchus labrax L.) using a marker-based pedigree. Aquaculture 275, 81-87.

Farbridge, K.J., Leatherland, J.F., 1992. Plasma growth hormone levels in fed and fasted rainbow trout (Oncorhynchus mykis) are decreased following handling stress. Fish Physiol. Biochem.10, 67-73.

Hinde, R.A., 1970. Animal behaviour: a synthesis of ethology and comparative psychology, $2^{\text {nd }}$ edn. McGraw-Hill, New York.

Humphrey, B., 1933. The nature of learning. Kegan Paul (Ed.). Trench \& Trubner, London.

Huntingford, F. A., Adams, C., Braithwaite, V. A., Kadri, S., Pottinger, T. G., Sandoe ,P., Turnbull, J. F., 2006. Current issues in fish welfare. J. Fish Biol. 68, 332-372.

Kindschi, G.A., 1988. Effect of intermittent feeding on growth of rainbow trout, Salmo gairdneri Richardson. Aquat. Fish. Manage. 19, 213-215.

Liebert, A.M., Schreck, C.B., 2006. Effects of acute stress on osmoregulation, feed intake, IGF-1, and cortisol in yearling steelhead trout (Oncorhynchus mykiss) during seawater adaptation. Gen. Comp. Endocr. 148, 195-202.

Mambrini, M., Sanchez, M.-P., Chevassus, B., Labbé, L., Quillet, E., Boujard, T., 2004. Selection for growth increases feed intake and affects feeding behaviour of brown trout. Livest. Prod. Sci. 88, 85-98.

McCormick, S.D., Shrimpton, J.M., Carey, J.B., O'Dea, M.F., Sloan, K.E., Moriyama, S., Björnsson, B.T., 1998. Repeated acute stress reduces growth rate of Atlantic salmon parr and alters plasma levels of growth hormone, insulin-like growth factor I and cortisol. Aquaculture 168, 221-235.

Metcalfe, N.B., Thorpe, J.E., 1992. Anorexia and defended energy levels in over-wintering juvenile salmon. J. Anim. Ecol. 61, 175- 181. 
Miglavs, I., Jobling, M., 1989. Effects of feeding regime on food consumption, growth rates and tissue nucleic acids in juvenile Arctic charr, Salvenilus alpinus, with particular respect to compensatory growth. J. Fish Biol. 34, 947-957.

Millot, S., Bégout, M.-L., Person-Le Ruyet, J., Breuil, G., Di-Poï, C., Fievet, J., Pineau, P., Roué, M., Sévère, A., 2008. Feed demand behavior in sea bass juveniles: effects on individual specific growth rate variation and health (inter-individual and inter-group variation). Aquaculture 274, 87-95.

Overli, O., Korzan, W.J., Hoglund, E., Winberg, S., Bollig, H., Watt, M., Forster, G.L., Barton, B.A., Overli, E., Renner, K.J., Summers, C.H., 2004. Stress coping style predicts aggression and social dominance in rainbow trout. Horm. Behav. 45, 235-241.

Overli, O., Pottinger, T.G., Carrick, T.R., Overli, E., Winberg, S., 2002. Differences in behaviour between rainbow trout selected for high- and low-stress responsiveness. J. Ex. Biol. 205, 391-395.

Overli, O., Winberg, S., Pottinger, T.G., 2005. Behavioural and neuroendocrine correlates of selection for stress responsiveness in rainbow trout - a review. Integr. Comp. Biol. 45, $463-474$

Pankhurst, N.W., Van der Kraak, G., 1997. Effects of stress on reproduction and growth. In: Iwana, G., Pickering, A., Sumpter, J., Schreck, C. (Eds.). Fish Stress and Health in Aquaculture Cambridge University Press, Cambridge. pp.73-94.

Parker, N.C., 1984. Chronobiologic approach to aquaculture. T. Am. Fish. Soc. 113, 545-552.

Peeke, H.V.S., Petrinovich, L., 1984. Habituation, sensitization and behaviour. Academic Press, New York.

Pickering, A.D., Pottinger, T.G., 1989. Stress responses and disease resistance in salmonid fish: effects of chronic elevation of plasma cortisol. Fish Physiol. Biochem. 7, 253-258. 
474 Pickering, A.D., Pottinger, T.G., Sumpter, J.P., Carragher, J.F., Le Bail, P.Y., 1991. Effects of acute and chronic stress on the levels of circulating growth hormone in the rainbow trout, Oncorhynchus mykiss. Gen.Comp.Endocr. 83, 86-93.

Pickering, A.D., Stewart, A., 1984. Acclimation of the interregnal tissue of the brown trout Salmo trutta L., to chronic crowding stress. J. Fish Biol. 24, 731-740.

Pottinger, T.G., Pickering, A.D., 1997. Genetic basis to the stress response: selective breeding for stress-tolerant fish. In: Iwama, G.K., Pickering, A.D., Sumpter, J.P. and Schreck, C.B (Eds.). Fish Stress and Health in Aquaculture. Cambridge University Press, Cambridge. pp 171-193.

Pottinger, T.G., 2003. The selection of trout for high and low responsiveness to stress: progress and prospects. Trout News, CEFAS 36, 14-16.

Pottinger, T.G., Carrick, T.R., 1999. Modification of the plasma cortisol response to stress in rainbow trout by selective breeding. Gen. Comp. Endocr. 116, 122-132.

Price, E.O., 1984. Behavioural aspects of animal domestication. Q. Rev. Biol. 59, 1.

Quinton, J.C., Blake, R.W., 1990. The effect of feeding cycling and ration level on the compensatory growth response in rainbow trout, Oncorhynchus mykiss. J. Fish Biol. 37,

Sánche-Vázquez, F.J., Madrid, J.A., Zamora, S., 1995. Circadian rhythms od feeding activity in sea bass, Dicentrarchus labrax L.: Dual phasing capacity of diel demand-feeding pattern. J. Biol. Rhythm. 10, 256-266.

494 Southgate, P., Wall, T., 2001. Welfare of farmed fish at slaughter. In Practice 23, 277.

495 Spieler, R.E., 1977. Diel and seasonal changes in response to stimuli: a plague and a promise 496 for mariculture. P. World Maricult. Soc. 8, 865-873.

497 Thorpe, W.H., 1963. Learning and instinct in animals, $2^{\text {nd }}$ edn. Methuen, London. 
498 Vandeputte, M., Dupont-Nivet, M., Haffray, P., Chavanne, H., Cenadelli, S., Parati, K., Vidal, 499 M.-O., Vergent, A., Chatain, B., 2009. Response to domestication and selection for 500 growth in the European sea bass (Dicentrarchus labrax) in separate and mixed tanks. $501 \quad$ Aquaculture 286, 20-27.

502

503

504

505

506

507

508

509

510

511

512

513

514

515

516

517

518

519

520

521

522 


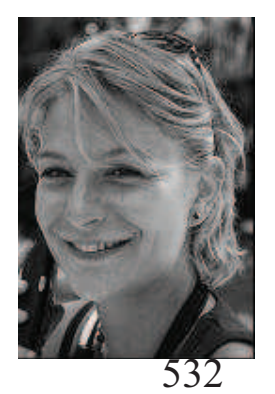

S. Millot, $\mathrm{PhD}$ in Oceanography from Ifremer and University of La Rochelle, France. Master degree in Biology of Behaviour from the University of Paris XIII, France.

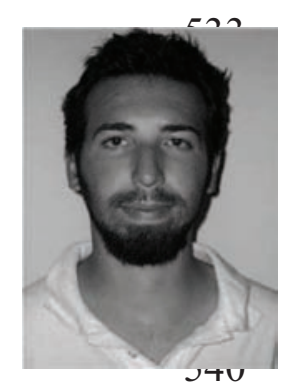

S. Péan, Second-year Ph.D. Student in Oceanography from Ifremer and University of La Rochelle, France. Master degree in Coastal Ecology from the University of La Rochelle, France.

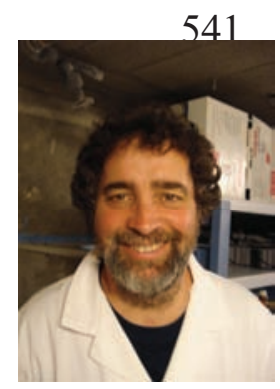

D. Leguay, engineer at Ifremer, with specialities in design, realization and development of scientific tools in the fields of ecotoxicology, physiology and fish welfare.

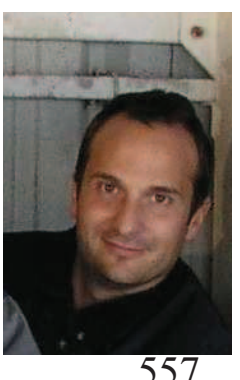

A. Vergnet, engineer at Ifremer, with specialities in design, realization and development of scientific tools in the fields of in aquaculture of marine fishes.

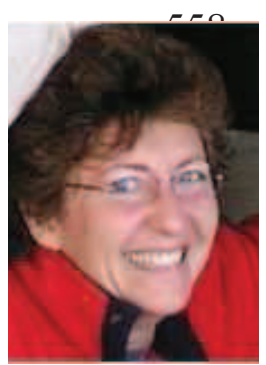

Béatrice Chatain, $\mathrm{PhD}$, is a senior scientist in aquaculture of marine fishes, with specialities in larval zootechny and genetics. She has coordinated $4 \mathrm{EU}$ research projects in the field of sea bass genetics.

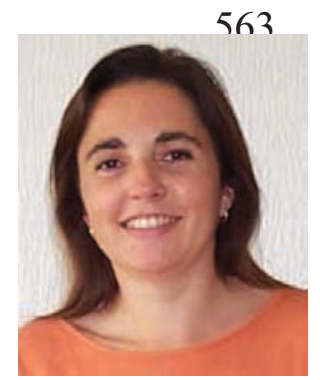

Marie-Laure Bégout, $\mathrm{PhD}$, is a senior scientist studying biological basis of behavioral adaptation and analysing underlying physiological mechanisms. She has participated in several Welfare EU projects. 
Table 1: Stress treatment timetable. Netting: pursuing fish with a net during $1 \mathrm{~min}$; light on: switching on the light for $2 \mathrm{~s}$ during the night; light off: switching off the light for $2 \mathrm{~s}$ during the day; bird: overflying a bird predator silhouette above the tank during $30 \mathrm{~s}$.

\begin{tabular}{|c|c|c|c|c|}
\hline \multirow[b]{2}{*}{$\begin{array}{c}\text { Experimental } \\
\text { day }\end{array}$} & \multicolumn{4}{|c|}{ Hour of the day } \\
\hline & At 01:00 & At 04:00 & At $10: 00$ & At $14: 00$ \\
\hline 35 & \multicolumn{4}{|c|}{ Measuring day } \\
\hline 36 & & & & \\
\hline 37 & light on & & & \\
\hline 38 & light on & & & \\
\hline 39 & light on & light on & & \\
\hline 40 & & & & \\
\hline 41 & light on & & & \\
\hline 42 & & light on & netting & \\
\hline 43 & & light on & & netting \\
\hline 44 & light on & & & light off \\
\hline 45 & & light on & netting & \\
\hline 46 & light on & light on & & \\
\hline 47 & & light on & & \\
\hline 48 & light on & & & \\
\hline 49 & & light on & & \\
\hline 50 & & light on & & \\
\hline 51 & light on & & netting & light off \\
\hline 52 & & light on & & netting \\
\hline 53 & light on & light on & & \\
\hline 54 & & light on & & \\
\hline 55 & light on & & bird & netting \\
\hline 56 & & light on & & \\
\hline 57 & & light on & & bird \\
\hline 58 & light on & & netting & light off \\
\hline 59 & & light on & & \\
\hline 60 & light on & light on & & \\
\hline 61 & & light on & & \\
\hline 62 & light on & & & bird \\
\hline 63 & & $\overline{\mathrm{Me}}$ & day & \\
\hline 64 & & light on & & \\
\hline 65 & light on & & & light off \\
\hline 66 & & light on & & \\
\hline 67 & light on & light on & & \\
\hline 68 & & light on & & \\
\hline 69 & light on & & bird & \\
\hline 70 & & light on & & netting \\
\hline 71 & & light on & netting & \\
\hline 72 & light on & & netting & light off \\
\hline 73 & & light on & & \\
\hline 74 & light on & light on & & \\
\hline 75 & & light on & & \\
\hline 76 & light on & & & bird \\
\hline 77 & & light on & bird & \\
\hline 78 & & light on & & netting \\
\hline 79 & light on & & netting & light off \\
\hline 80 & & light on & & bird \\
\hline 81 & light on & light on & & \\
\hline 82 & & light on & & \\
\hline 83 & light on & & bird & netting \\
\hline 84 & & light on & netting & \\
\hline 85 & & light on & & netting \\
\hline 86 & light on & & & light off \\
\hline 87 & & light on & & bird \\
\hline 88 & light on & light on & & \\
\hline 89 & & light on & & \\
\hline 90 & & & & \\
\hline 91 & & Final & day & \\
\hline
\end{tabular}




\section{Figure captions:}

\section{Figure 1. Amount of food intake over time}

Mean (+ SE) intaken (demanded - wasted) food amounts for 4 strains of sea bass: Wild, Domesticated, Selected A and Selected B. In white: during a control period (period 2; 21 days), in light grey: during the first period of stress treatment (period 3; 28 days), in dark grey during the second period of stress treatment (period 4; 28 days).

\section{Figure 2. Growth performance over time}

Variations over time of mean ( \pm SE) body mass (A), specific growth rate, SGR (B) and body condition factor, K (C) for Wild, Domesticated, Selected A and Selected B sea bass strains. In white: during a control period (period 2; 21 days), in light grey: during the first period of stress treatment (period 3; 28 days), in dark grey during the second period of stress treatment (period 4; 28 days). Letters indicate significant differences between date for each strain (ANOVA and Newman \& Keuls test, $\mathrm{p}<0.05$ ).

\section{Figure 3. Feeding rhythm over time}

Pattern of daily mean $( \pm \mathrm{SE})$ feed demands per hour during a control period (period $2 ; 21$ days; A), during the first period of the stress treatment (period 3; 28 days; B) and during the second period of the stress treatment (period 4; 28 days; C) for Wild, Domesticated, Selected $A$ and Selected $B$ sea bass strains. The grey boxes indicate the night period. 


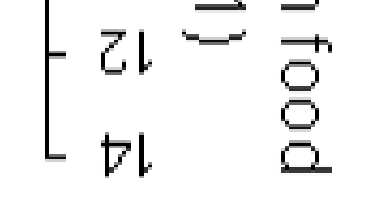

\section{в peqगe|ə⿹s}

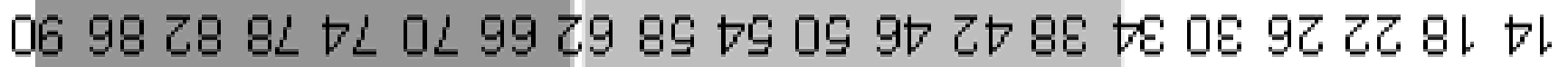

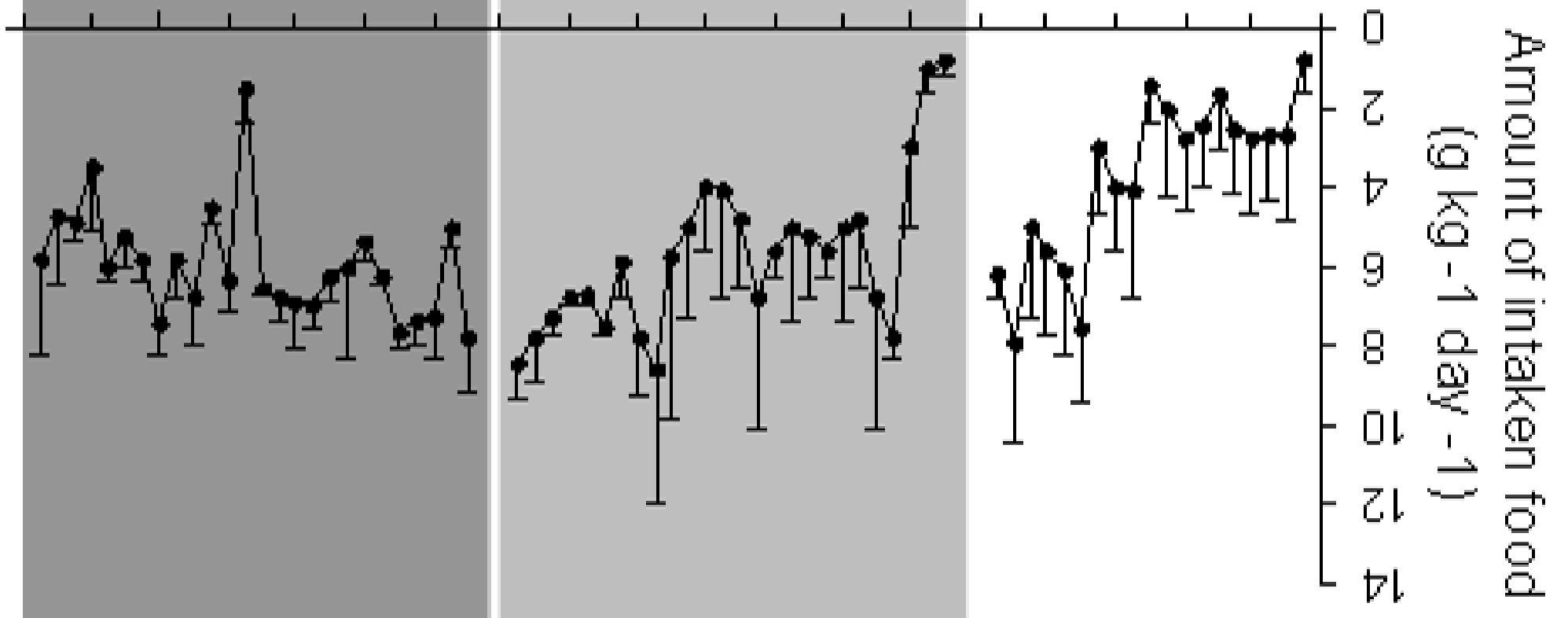

\section{$\forall$ pey키코}

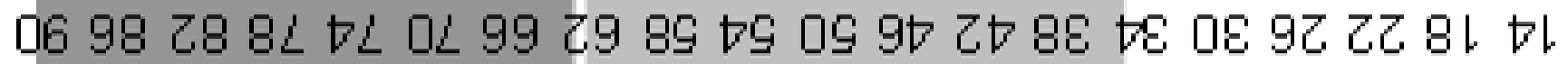

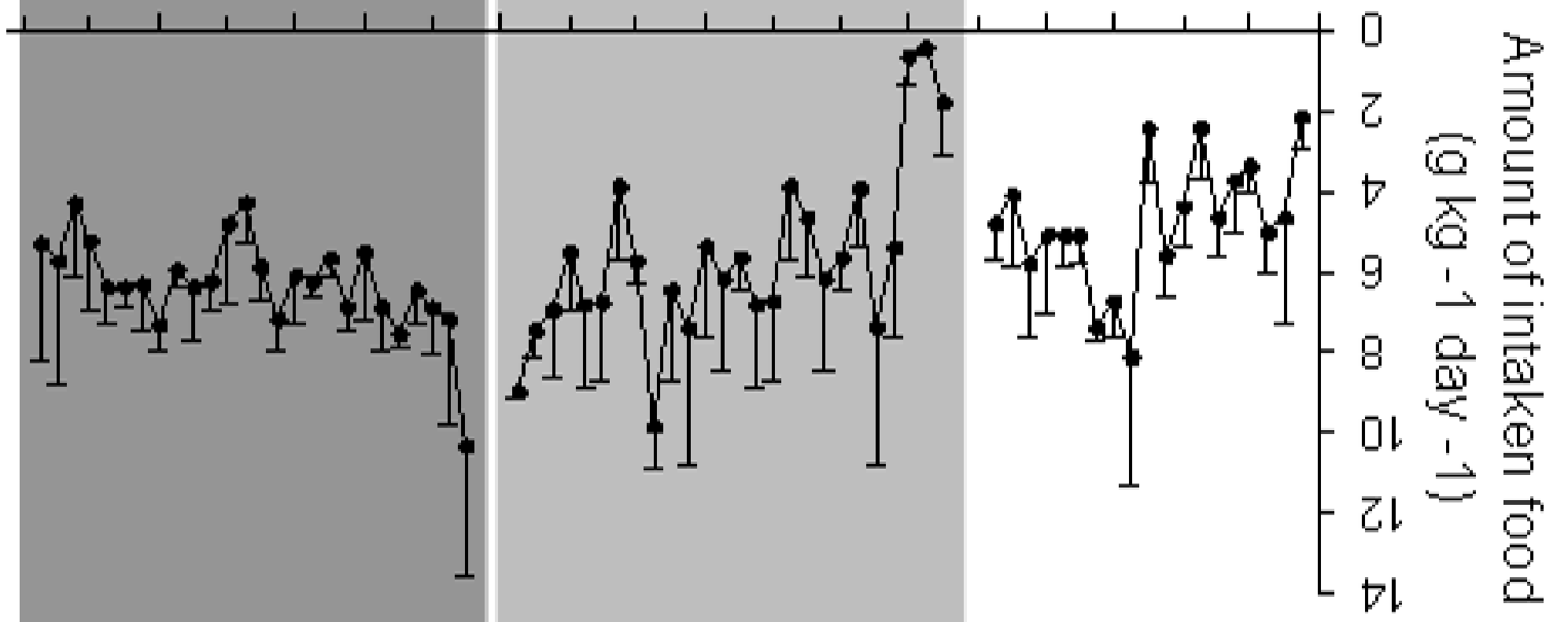

pәтеэ!ฺsemog

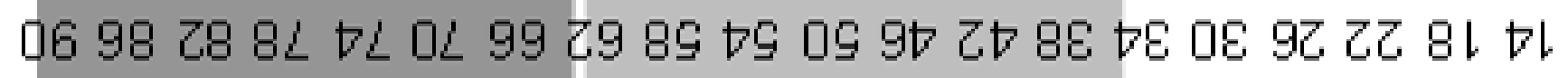



